\title{
Enveloping of Catalyst Powder by Ionomer for Dry Spray Coating in Polymer Electrolyte Membrane Fuel Cells
}

\author{
Krishan Talukdar*a, Stefan Helmly ${ }^{\mathrm{a},}$, Mathias Schulze ${ }^{\mathrm{a}}$, Daniel G. Sanchez ${ }^{\mathrm{a}}$, Michael \\ Handl $^{b}$, Renate Hiesgen ${ }^{b}$, Jürgen Kraut ${ }^{b}$, K. Andreas Friedrich ${ }^{a, c}$ \\ a. German Aerospace Center (DLR), Institute of Engineering Thermodynamics \\ Pfaffenwaldring 38-40 Stuttgart, 70569, Germany
}

b. University of Applied Science Esslingen, Faculty of Basic Science, Kanalstrasse 33, 75728, Esslingen, Germany

c. University of Stuttgart, Institute of Building Energetics, Thermal Engineering and Energy Storage (IGTE), Pfaffenwaldring 31, 70569 Stuttgart, Germany

\begin{abstract}
:
This study presents innovative concepts for improving performance of membrane electrode assemblies (MEAs) prepared by the dry-spraying method introduced by the German Aerospace center (DLR). Dry-spraying is a time and cost effective method that involves solvent-free spraying of catalyst powder on polymer electrolyte membrane. The issue which is resolved in this work is the large ionomer particle size in the conventional method. With mechanical grinding, particle size of the ionomer less than $100 \mathrm{~nm}$ were not been achieved. However, here the reactive interface of dry-sprayed MEA is optimized by improving ionic conductivity. Our approach is to modify a carbon support by partially enveloping with Nafion ${ }^{\circledR}$ ionomer followed by incorporating Pt black with it. Additionally, commercial catalyst powder was also modified by two-step preparation process with Nafion ${ }^{\circledR}$ dispersion. In this research, both of these modified powders are sprayed over membrane; hot-pressed; characterized, and have shown improved ionic network and distribution, which corresponds to their higher performances. The improvement in the performance does not correlate with electrode surface area but with the ionomer resistance of the catalytic layer. Therefore, with this study we demonstrate a pathway and methodology to further improve performance by optimizing ionomer structure and networks in the catalytic layer.
\end{abstract}


Keywords: Dry spraying, dry ink preparation, ionomer film, Nafion ${ }^{\circledR}$ coating, PEM fuel cell Corresponding author Phone: +49-711-6862-567; e-mail: krishan.talukdar@dlr.de

\section{Introduction:}

1.1 Energy demand has become one of the most serious concerns of modern society due to the problems related with greenhouse gas emissions and the depletion of fossil fuels. In this context fuel cells (FCs) in particular, Proton Exchange Membrane Fuel Cells (PEMFCs) can be considered as one vital technology to reach the goals of the European Union to reduce greenhouse gas emissions by $80 \%$ by 2050 . Fuel cells convert chemical energy directly into electricity which is more efficient and environmentally friendlier than combustion engines in automotive applications [1], and fuel cells can be emission-free with green hydrogen. Moreover, fuel cells have cost and weight advantages compared to batteries at large sizes, and enable fast charging within 3 min [2]. Polymer electrolyte membrane fuel cells (PEMFCs) are attractive because of their high power density, flexibility to operate in low temperature and high dynamical response. The interior of this electrochemical cell consists of a membrane electrode assembly (MEA), a proton exchange membranes (PEM) in-between catalyst and gas diffusion layer (GDL) electrode pairs. This assembly needs to provide high intrinsic activities for the oxidation of hydrogen at the anode side and reduction of oxygen at the cathode side. In order to achieve high performance, the transport of gases as well as the conductance of electrons, and protons must be optimized to provide efficient transport to and from the interface of the electrochemical reactions. The architecture of electrodes for PEMFC's is an intricate balancing of transport media and catalytic activity. The economic competitiveness of PEMFCs is hindered by the high cost of the materials, in particular the platinum catalyst as standard material dominates the cost of mass manufacture, which may represents approximately $45 \%$ of the overall costs [3]. The costs of electrode fabrication should be reduced by different approaches such as reducing or avoiding platinum (Pt) loading on both 
electrodes and superior catalyst utilization. Nevertheless, even at low loading Pt electrodes still contribute significantly to the comprehensive costs of the system if mass production scenarios are evaluated. Hence, to make this technology a viable energy source, a reduction of Pt loading in the catalyst layers without loss in performance and durability is essential. Performance of fuel cells usually depends on the composition and fabrication method of catalyst layer. Thin catalyst layers can be produced by numerous coating techniques, saving expensive catalyst materials [4].

Ionomer is added to the catalyst layer to facilitate proton transfer and as binder. The effect of ionomer loading in the $\mathrm{CL}$ on cell performance has been examined for conventional electrodes. The state of the art Nafion ${ }^{\circledR}$ loading is approximately $30 \mathrm{wt} \%$ with respect to the solid catalyst particles $[5,6,7]$. Shukla et al. shows the importance of an optimal Nafion ${ }^{\circledR}$ loading with an efficient balance between proton transport and gas transport for superior fuel cells [8]. If the ratio of Nafion ${ }^{\circledR}$ decreases from the optimum level, it causes kinetic loss in low current density whereas for a higher ratio of $\mathrm{Nafion}^{\circledR}$, it causes mass transport losses at high current densities. For state of the art idealized "model" structure of the electrode, a very thin ionomer film partly covers the $\mathrm{Pt} / \mathrm{C}$ surface. This thin film of ionomer facilitates the transport of reactant gases through pores to the catalyst surface, followed by protons from the catalyst through ionomer network, and electrons via carbon support. Above-mentioned phenomena simultaneously create the indispensable ionomer catalyst interfaces to maximize catalyst utilization [9]. The transport of oxygen species as product of the oxygen reduction reaction (ORR) permeates mainly through ionomer-free parts of the $\mathrm{Pt} / \mathrm{C}$ agglomerates [10]. Transport of protons [11,12] is controlled by the thickness as well as the continuity of the ionomer on the catalyst surface and hydrophilic networks in the catalyst layer (CL). Finally, the transport of electrons is related to the continuity of the carbon particle network [13] and the contact. 

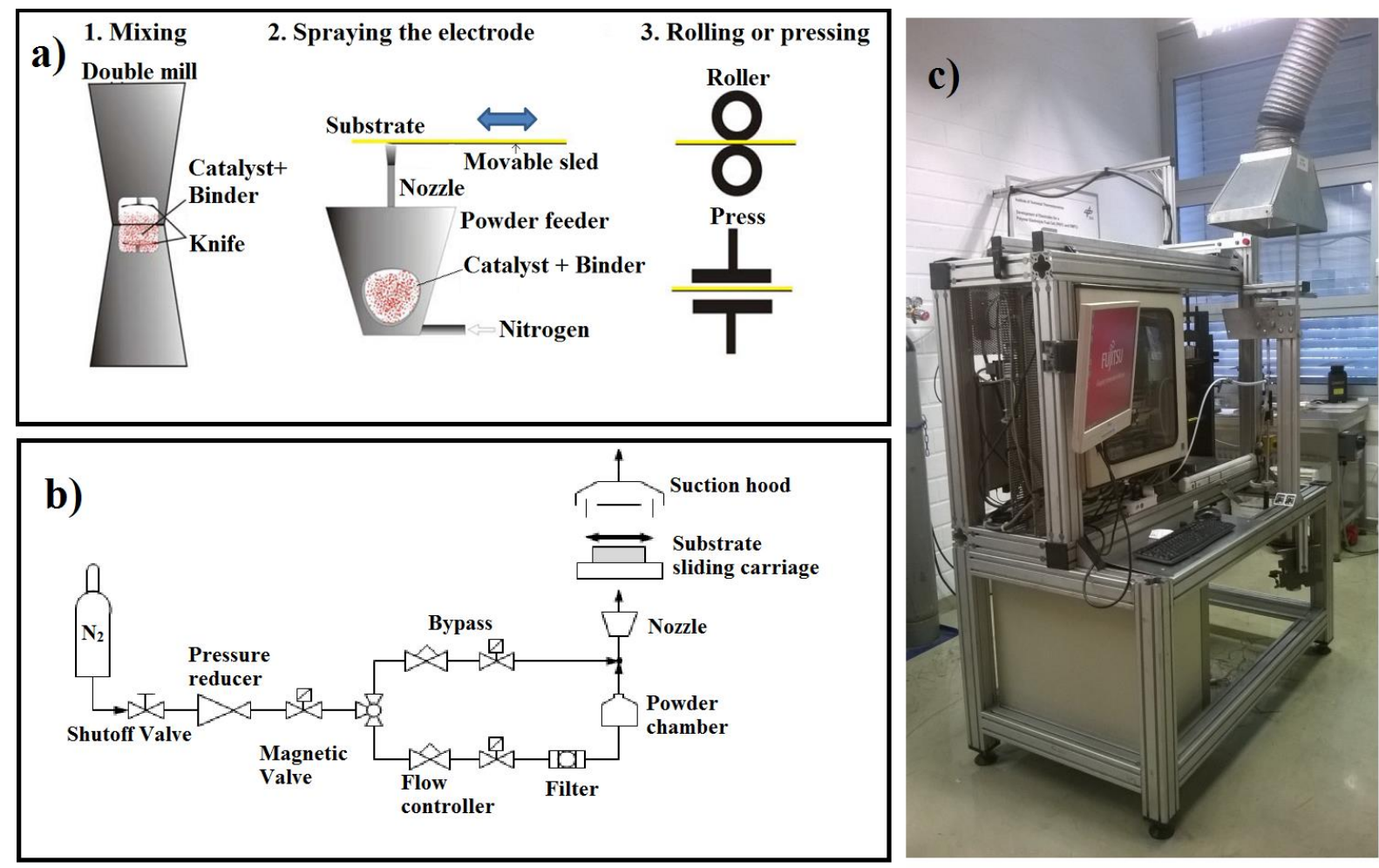

Figure 1: a) Schema of dry powder spraying MEA manufacturing process, b) flow diagram of dry spraying facility, c) image of the DLR dry spraying machine.

1.2 There are numerous catalyst coating techniques based on various substrates, particles morphology and method of coating. All of the MEA coating techniques have their own advantages and disadvantages. The PEM research group of DLR developed a dry layer preparation method for fabricating catalyst layers bound by either PTFE or Nafion ${ }^{\circledR}$ by spraying the atomized dry mixture of catalyst with the aid of nitrogen gas stream onto either GDL or membrane as described by Güzlow et al. [14]. In powder spraying, the principle of electrostatic forces, especially between electronic conductors and insulators, is used to form an adhesive powder layer onto a substrate. In the DLR process, the powder is tribologically charged initially by laboratory knife milling process, while atomization takes place in the separating funnel and inside the pipes during the spray process. The charged powder is subsequently fed to the coating facility which sprays the powder via a nozzle onto the substrate, commonly the membrane. Subsequently, the assembly is hot-pressed or rolled $[15,16]$. Figure 1 demonstrates the in-house dry spraying facility in DLR. This procedure is 
very fast and easy to handle, as a dry process avoids the use of any solvents and drying steps during MEA preparations and allows continuous production for industrial purpose. The bottleneck of this coating technique is the ionomer particle size, hydrophilicity of ionomer particles and its agglomeration. Inhomogeneous distribution and agglomeration of particles cause less active catalytic surface area in the reactive interface of the electrode compared to the conventional and commercial electrodes. Preparation of Nafion ${ }^{\circledR}$ powder is very crucial due to requirement of cryogenic grinding by means of an impactor mill in liquid nitrogen. Until now, ionomer particle sizes of down to $1 \mu \mathrm{m}$ can be reached, and the size distribution is unsatisfactorily broad with this technique. As a consequence of large particle size and heterogeneous distribution up to $50 \mu \mathrm{m}$, high performance electrode membrane assemblies could not be accomplished. According to literature [13], standard electrodes should have ionic film dimension $<10 \mathrm{~nm}$, which will allow sufficient proton transport and gas permeation. The resulting bigger Nafion ${ }^{\circledR}$ particles e.g. $(5$ to $50 \mu \mathrm{m})$ or agglomerations apparently cover many of the active catalytic sites during the hot-press procedure and as a result, uniform porosity and utilization of active area are lost. In addition, heterogeneous hydrophilic/ hydrophobic regions may causes isolation of $\mathrm{Pt}$, local flooding, pinholes and water-gas transport issues. Not surprisingly often dry sprayed MEAs with low Pt loading showed flooding problem and unstable performance during operation.

\section{Approach:}

2.1 To overcome these issues of the powder spraying technique, we modified the technique with a single approach in order to achieve two following aspects; first, is to enhance the Nafion ${ }^{\circledR}$ dispersion inside the electrode, and second, is to enwrap the catalyst particles partially with a thin film of ionomer. The approach is replacing solid ionomer by introducing liquid ionomer dispersion. Consequently it facilitates catalytic activity, increased proton 
conductivity and gas access. This crucial approach improves the active sites of the catalyst layer and increases the performance significantly. Here we tried to eliminate the step of grinding solid Nafion ${ }^{\circledR}$ particles, and as an alternative we introduced commercially available Nafion ${ }^{\circledR}$ dispersion in the catalyst powder preparation procedure. In this article, we showed two favorable process variants, one is adding ionomer solution with carbon support, which will partially cover the carbon particles and subsequently disperse or mix the platinum black with that support to make $40 \%$ Pt on carbon support. Another is using ionomer solution to partially coat the total catalyst-support mixture purchased commercially, and eventually make a dry powder out of it. We herein fabricated MEAs by dry spraying process with standard type and modified catalyst powder with corresponding in-situ and physical characterization.

2.2 Targeting an electrode structure according to an ideal electrode architecture $[17,18]$, we attempted to make a better network among ionomer, platinum, carbon, water and feed gasses with respect to the TPB postulation. It is assumed that, strings or filaments of ionomer attached to catalyst particles or partially coated catalyst particles with ionomer will increase the electrochemically active platinum surface for reaction. In both cases, the catalytic layer should avoid aggregation of particles and keep a good balance between hydrophilic and hydrophobic region. As our aim is to coat catalyst particles with ionomer, we will consider catalyst particles as a pigment and ionomer as a binder according to the theory of coating technology. The chief purpose of pigment dispersion is to break down aggregates and form stable dispersions of optimal sized pigment particles. Here, we introduced ionomer dispersion to partially coat the catalyst particles. A very important issue which is most of the time underestimated is the calculation of a coating ratio where ionomer acts as a binder and particles as pigments. The coating ratio and its consequence can be estimated from the pigment-volume-concentration (PVC) ratio.

$\mathrm{PVC}=\frac{V(\text { pigments })}{V(\text { total })}=\frac{V(\text { pigments })}{(\text { V(pigments })+V(\text { binder } / \text { Ionomer }))}$ 
The so-called critical-pigment-volume-concentration (CPVC) is the transition point, from the pigments being completely covered by a binder to a state where they are not [19]. It is not really possible to calculate this value, but one can easily determine this value experimentally, as the mechanical and optical properties of the coating dramatically change at that point. As the PVC value increases beyond the CPVC value, the fewer amounts of pigment particles being covered by binder and increases porosity. On the contrary, if PVC value decreases from CVPC value, the coating will lose its porosity and the binder will isolate the pigment particle completely. We computed the PVC values of our ink theoretically by calculating individually the volume of Pt-nano particle, carbon support and dry ionomer. The values are evaluated with above equation:-

- PVC value of the modified commercial catalyst is $82 \%$.

- $\mathrm{PVC}$ value of the modified carbon support is $82 \%$

The value of the CPVC is governed by several factors, including particle size, particle size distribution and particle shape as well as by the chemical properties of the particle surface. Ideally for spherical particles of uniform particle size a maximum CPVC of $74 \%$ is calculated [20]. It means any coating composite of spherical particles along with binder having PVC value less than $74 \%$ will be totally covered by the binder, and a coating composite having PVC value higher than $74 \%$ will have partial covering of binder over spherical particles causing porous structure. Both of the values of our modified powders are above the average CPVC values thus ensure the partial covering of the ionomer. Due to the low binder content we ensure availability of void space, therefore enabling permeability and interface roughness. The standard dry powder preparation technique does not include liquid $\mathrm{Nafion}^{\circledR}$ as a binder so PVC value method does not apply. 


\begin{tabular}{|c|c|c|}
\hline \multicolumn{3}{|c|}{ Electrode powder preparation } \\
\hline Standard [15] & Catalyst modification & Support modification \\
\hline $\begin{array}{l}{ }^{*} \text { Grinding Nafion pellets to } \\
\text { fine powder by Cryogenic Mill } \\
{ }^{*} \text { Hispec } 4000+\text { Nafion } \\
\text { powder (Knife Milling) } \\
\text { Dry powder Pt/C } 40 \mathrm{wt} \% \text { : } \\
\text { Nafion ( } 70: 30)\end{array}$ & $\begin{array}{l}\text { *Hispec } 4000+\text { Ultrapure } \\
\text { water (Dispersion) } \\
* \text { Hispec } 4000 \text { catalyst } \\
\text { dispersion }+ \text { Nafion } 5 \% \\
\text { dispersion }\left(\text { Colloidal Sol }{ }^{\mathrm{n}} \text { ) }\right. \\
\text { *Drying the dispersion } \\
\text { * Grinding it in Cryogenic Mill } \\
\text { D Dry powder Pt/C 40wt } \%: \\
\text { Nafion }(70: 30)\end{array}$ & $\begin{array}{l}\text { *Vulcan Xc-72+ } \\
\text { Ultrapure water (Dispersion) } \\
\text { *Vulcan XC-72 + Nafion 5\% } \\
\text { dispersion (Colloidal Solution) } \\
\text { *Drying the dispersion } \\
\text { * Grinding it in Cryogenic Mill } \\
\text { *Hispec } 1000, \text { Pt-b + Modified } \\
\text { support (Knife Milling) } \\
\text { D Dry powder Pt/C 40wt\% : } \\
\text { Nafion }(70: 30))\end{array}$ \\
\hline
\end{tabular}

Table 1: Different route of catalyst powder preparation for dry spraying MEA

\section{Experimental:}

3.1 MEA Preparation: DLR patented technique for the fabrication of catalyst coated membrane $(\mathrm{CCM})$ is spraying a dry catalytic layer directly onto the membrane $[14,15]$. The preparation technique for MEAs is divided into three main steps: a) preparation of the electrode powder, b) dry spraying the powder onto the membrane, c) hot rolling or pressing the membrane with the gas diffusion layers [21,22]. Fabrication procedure of all the techniques is summarized in table 1 . Nafion ${ }^{\circledR}$ pellets/ $5 \mathrm{wt} \%$ solution/Nafion ${ }^{\circledR}$ XL membrane (Ion Power Inc.), 40 wt\% Pt/C Hispec 4000 (Alfa Aesar), Pt black Hispec 1000 (Alfa Aesar), Vulcan XC-72 (CABOT), isopropanol (VWR), ultrapure water (VWR), PTFE sheets (205 $\mu \mathrm{m}$, Bohlender) were purchased commercially. Mixing was done by $\mathrm{S} 60 \mathrm{H}$ Elmasonic ultrasonic bath. Nafion ${ }^{\circledR}$ XL membranes were used as substrate for powder spraying then immediately hot pressed with GDL (BC-25, SGL Carbon) at $160^{\circ} \mathrm{C}$ for 5 minutes with 690 $\mathrm{Ncm}^{-2}$ by hot press (Vgot) to make CCMs.

3.2 Catalyst modification: Hispec 4000 nano powder was dispersed in ultrapure water by sonication. Afterward, Nafion ${ }^{\circledR} 5 \mathrm{wt} \%$ solution was dropwise added to the dispersion, placed 
on a sonicator so that catalyst/ Nafion ${ }^{\circledR}$ ratio of $70: 30$ is maintained. Then the mixture was sonicated again and dried at $80^{\circ} \mathrm{C}$ in air for one day in normal oven. Eventually, the solid powder was ground by means of cryogenic mill (6850 Freezer Mill) to avoid the compression molding of ionomer and sprayed via the dry spraying device to fabricate CCM.

Support modification: Vulcan XC-72 is a widespread Pt support for PEMFC application due to its high surface area and good electrical properties. It is a hydrophobic material, so it is dispersed in ultrapure water by several steps of mechanical shaking and sonication. Afterward, Nafion ${ }^{\circledR}$ was added dropwise so that catalyst/ Nafion ${ }^{\circledR}$ ratio of 70:30 is maintained and then the mixture was sonicated. Mechanical shaking followed as well as sonication for three more times. The mixture was dried at $80^{\circ} \mathrm{C}$ in air for one day, and ground via a cryogenic mill to produce fine powder. Eventually, required amount of Pt black was added to the supporting powder so that the ratio of Pt to carbon support was 40:60. Then the powders were mixed via a knife mill and dry sprayed via the dry spraying device onto the membrane. For all MEAs $0.3 \mathrm{mgcm}^{-2} \mathrm{Pt}$ loading was maintained.

3.3 The MEAs were assembled in a graphite flowfield with gold coated bi-polar plate purchased from Electrochem, USA. MEAs were assembled with PTFE gaskets over the three meander two channel serpentine graphite flow field with $2 \mathrm{Nm}$ torque to each four $5 \mathrm{~mm}$ screws. Afterwards, single cell tests were performed in the test bench built and customized by DLR. Prior to testing, MEAs were conditioned at a potential $0.6 \mathrm{~V}$ and $0.3 \mathrm{~V}$ for 4 hours each. All the MEAs were examined in 50\% humidification and stoichiometric flow of $\lambda_{\mathrm{H} 2}: 1.5-\lambda_{\text {air }}$ : 3 during conditioning, polarization curve measurement and electrochemical impedance analysis. Galvanostatic polarization was measured with the holding time 3 min in each current density. Electrochemical impedance spectroscopy (EIS) was conducted with electrochemical work station IM6e (Zahner). Nyquist and Bode plots were determined in two different current densities of 0.1 and $0.5 \mathrm{Acm}^{-2}$ in the frequency range from $100 \mathrm{mHz}$ to $100 \mathrm{KHz}$ with the 
amplitude of $10 \mathrm{~mA}$ and $50 \mathrm{~mA}$ respectively. EIS at low current density shows predominantly the kinetic losses, mid current density shows dominantly the ohmic contribution, and high current density demonstrates the mass transport polarization. The ionic impedance of the electrode was also evaluated with special EIS measurement. In order to characterize ionic impedance, $10 \mathrm{ml} / \mathrm{min}$ hydrogen and nitrogen gas were fed into anode and cathode with $100 \%$ humidification. Ionic impedance was measured in $1 \mathrm{~V}$ potentiostatic condition with $10 \mathrm{mV}$ amplitude through $500 \mathrm{mHz}$ to $100 \mathrm{KHz}$ frequency, stated in the concerning literature $[23,24]$. According to the literature, at high frequencies a Warburg-like response ( $45^{\circ}$ slope) is observed, corresponding to ion conductivity in the catalyst layer. At low frequencies, the impedance plot curves up to a limiting capacitance response (vertical) which corresponds to the total capacitance and resistance of the catalyst layer. The ionic resistance, $R_{\text {ionic }}$, can be obtained from the length of the Warburg-like region projected onto the real impedance $\left(Z^{\prime}\right)$ axis (= $\left.R_{\text {ionic }} / 3\right)$ [24]. Three sets of MEAs were tested of each type and found that the results are reproducible for all characterizations. Cross-section of MEA was prepared by freezefractioning and ion cutting system (JOEL IB 19520/CCP). Catalyst powder and cross-sections were characterized by means of scanning electron microscope (JEOL JSM-7200F.) with $5 \mathrm{kV}$. We applied $\mathrm{N}_{2}$ adsorption in order to investigate the pore structures of the catalyst powders after addition of ionomer. The $\mathrm{N}_{2}$ physisorption, pore size distribution and B.E.T. analysis were performed by Thermo Finnigan/Sorptomatic 1990. 

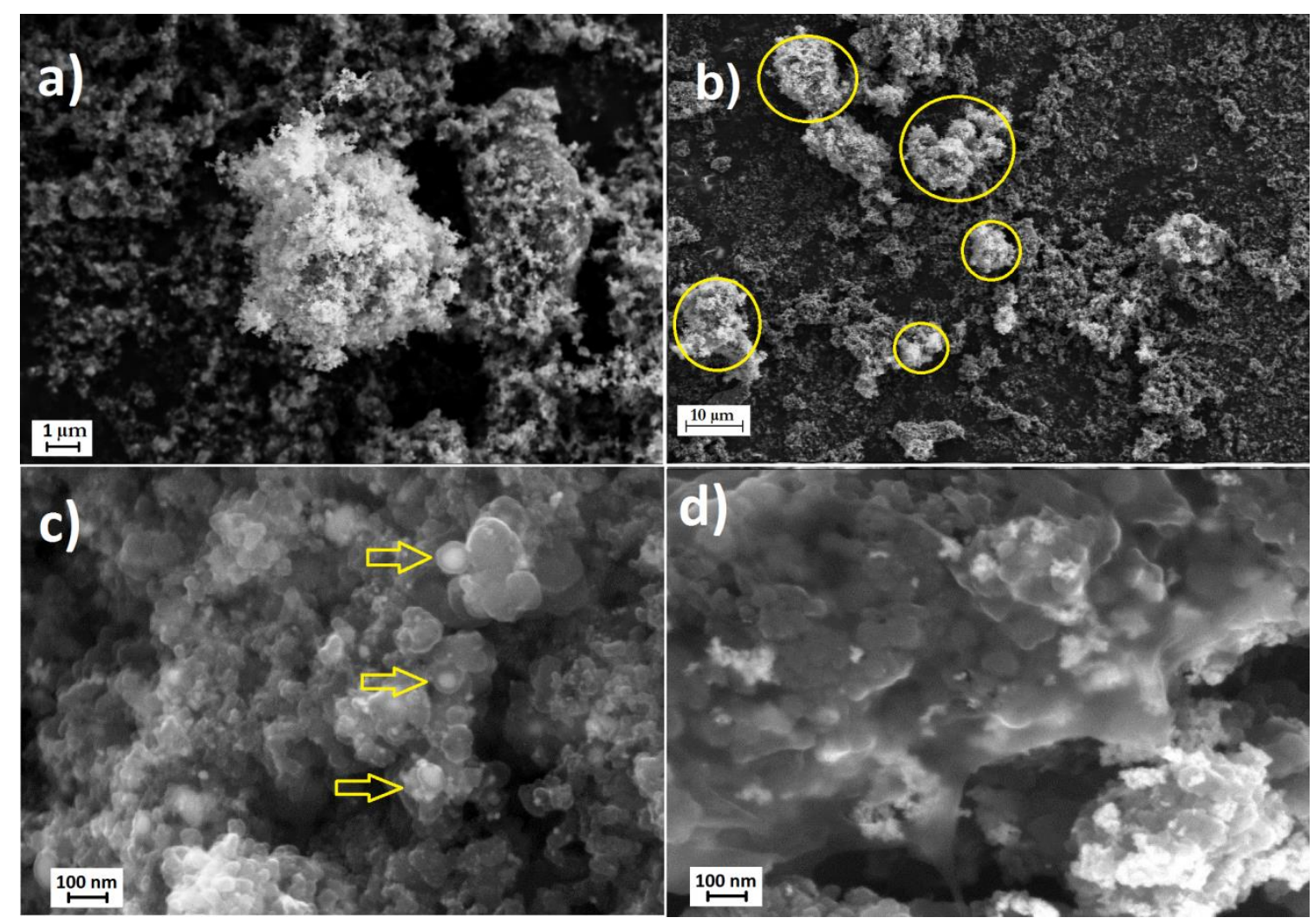

Figure 2: SEM images of different catalyst powders; a, b: Pt/C catalyst powder mixed with solid ionomer (standard route), c: Pt/C catalyst modified with liquid ionomer (catalyst modification route)- and d: catalyst support modified with liquid ionomer mixed with Pt black (support modification route).

\section{Result and Discussion:}

4.1 Fig. 2 (a) represents the standard dry-spray powder consisting of a 6-7 $\mu \mathrm{m}$ large particle agglomeration of Nafion ${ }^{\circledR}$. As mentioned earlier, it is challenging to avoid the substantial agglomeration of solid ionomer powder, which is hydrophilic and shows high selfadhesion. Some of the big agglomerates of Nafion ${ }^{\circledR}$ heterogeneously distributed all over the catalyst powder can be seen randomly with lower magnification of SEM which was circled in fig. 2 (b). This heterogeneity causes the lack of active sites, uniformity and uneven thickness of the catalyst layer. Consequently, this phenomenon attributes to uneven local current density and bad performance of MEA prepared with standard catalyst powder (shown later). Fig 2(c) 
shows a formation of thin ionomer coating around the $\mathrm{Pt} / \mathrm{C}$ particles which increase the zone of reactive interface and thereby enhances the performance. Fine film around the Pt particles like core-shell is observable in the image, where Pt particles are bright objects covered with transparent layer of Nafion ${ }^{\circledR}$ (marked by arrow). Whereas, fig. 2(d) shows the presence of thin ionomer film over the carbon support agglomerates, and bright platinum catalyst agglomerates are infused with them. In contrast, to standard powder, modified powders show more homogeneous distribution of platinum, carbon support and ionomer throughout the catalyst powder. As evaluated by the PVC calculation, despite that the modified catalyst (c) and support particles (d) were coated by thin film of liquid ionomer, the aggregated powders should retain enough porosity and coarseness because of their higher PVC values. Nevertheless, the ionomer coating causes many of the micro $(\leq 2 \mathrm{~nm})$ and mesopores $(2-50$ $\mathrm{nm}$ ) to be covered by ionomer, thus reducing the porosity of the powder. However, the better ionomer connection compensates this loss by improving the network of the reactive interface, which leads to improved performance of the modifications. Nonetheless, because of the inclusion of Pt black powder (which already contains some Pt agglomerates) to prepare support modified catalyst powder, there will be less Pt active surface area compared to the standard powder. Furthermore, in case of catalyst modified powder the thin film of ionomer covered most of the Pt particles, carbon support and some of their micro/ mesopores, which is the reason of reduction in surface area (explained in 4.2) shown via B.E.T. Both of the fig 2 (c and d) show that the thickness of ionomer films which covered the particles are well below $0.2 \mu \mathrm{m}$ and should not cause any diffusion problem [25]. If the ionomer films are thin enough, superior electrochemical activity of Pt can be assumed; however, if the ionomer is too thick, Pt will be isolated and be inactive $[19,25]$. Therefore, by controlling the thickness and condition of ionomer film around the catalyst particle, we can improve the performance of the MEA. 

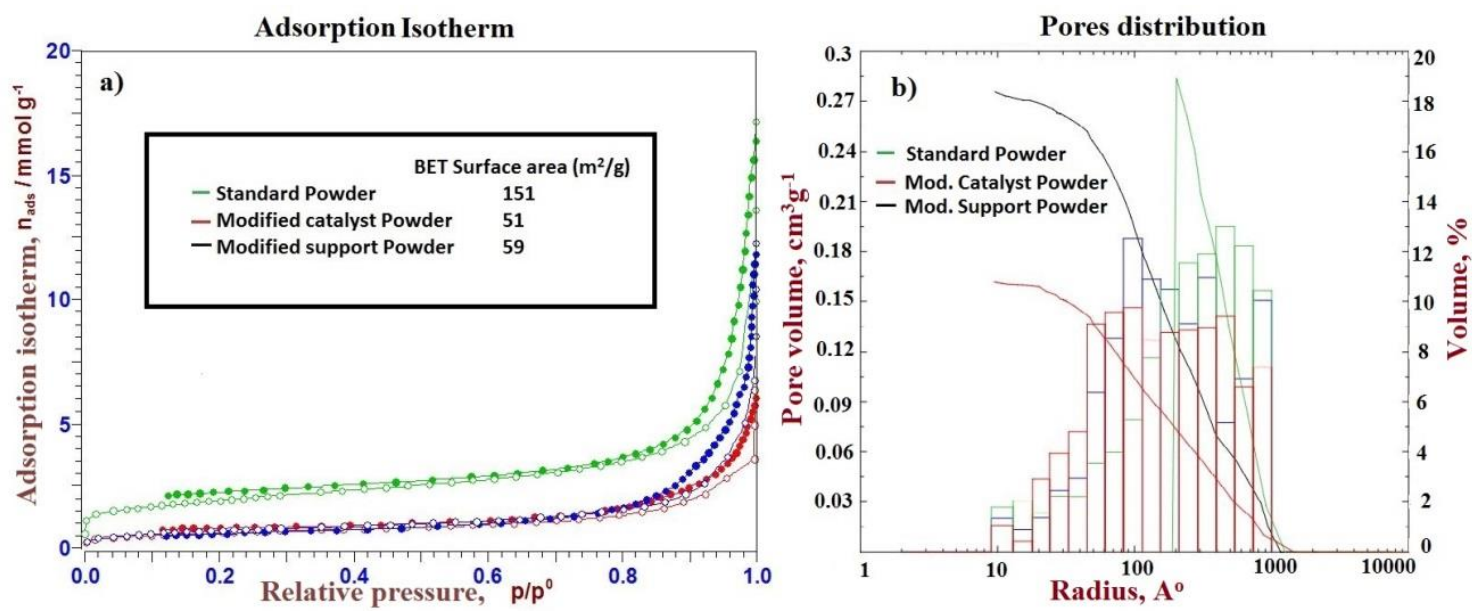

Figure 3: a) $\mathbf{N}_{2}$ adsorption-desorption isotherm and B.E.T. surface area measurement values (inset), b) pore size distributions of unmodified powder and powders modified by catalyst and support modifications.

4.2 Figure 3(a) shows the change of $\mathrm{N}_{2}$ adsorption isotherms of catalyst powders prepared with solid Nafion ${ }^{\circledR}$ and liquid Nafion ${ }^{\circledR}$ dispersion respectively. The amount of $\mathrm{N}_{2}$ adsorption was reduced by the ionomer addition for both of the modified powders. When dry Nafion ${ }^{\circledR}$ powder was mixed with $\mathrm{Pt} / \mathrm{C}$ powder, the mesopores and micropores of the $\mathrm{Pt}$ along with carbon support were intact. As a consequence, B.E.T. surface area shows a higher value 151 $\mathrm{m}^{2} / \mathrm{g}$. On the contrary, addition of liquid Nafion ${ }^{\circledR}$ forms an external film or coating over the Pt and carbon supports. Additionally, some of the liquid Nafion ${ }^{\circledR}$ even penetrates and blocks the internal micropores of the support which can be shown in the graph of pore size distribution in fig. 3(b). This blockage of micropores may improve the performance by impeding Pt nanoparticles to relocate into the internal pores where they will become inactive $[26,27]$. As a result, both modified catalyst powders prepared with liquid Nafion ${ }^{\circledR}$ show lower B.E.T. surface area, but better distribution of ionomer which ensures higher catalytic reaction area as well as better performance. 

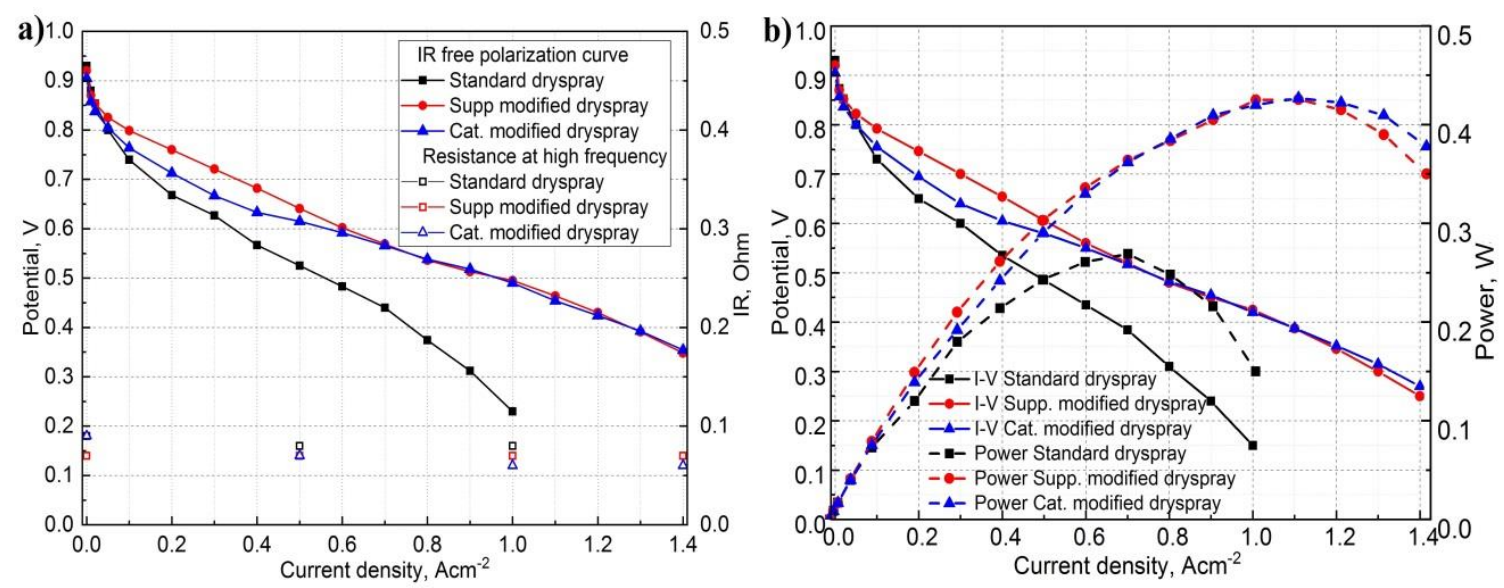

Figure 4: a) IR compensated current/voltage characteristics of MEA's prepared with different modified powders, b) current/voltage and power characteristics; reaction condition was following: cell temp. $80{ }^{\circ} \mathrm{C}, 50 \%$ humidified feed gas, system pressure 150 Kpa and stoichiometry was $\lambda_{\mathrm{H} 2}: 1.5-\lambda_{\text {air }}: 3$.

4.3 Current-voltage graphs of the different MEAs fabricated with distinctive catalyst powders were shown in fig. 4. IR corrected current-voltage curves are shown in fig 4(a) to compare the activation and mass transport losses. As the experiments were done in $1 \mathrm{~cm}^{2}$ test station, area specific resistances were directly calculated from high frequency impedance at several current density points shown on the secondary axis of fig 4(a). Performance and power curves of different MEAs prepared with distinctive preparation techniques are also displayed in figure 4 (b). Both of these polarization curves further supports the fact that MEA prepared with catalyst powders and liquid Nafion ${ }^{\circledR}$ solution exhibit better performance comparing to the standard powder. Significant difference is observed in mass transport region in higher current density where standard dry sprayed MEA shows no performance above 1 $\mathrm{A} / \mathrm{cm}^{2}$ current density, because of limiting diffusion. Support modified and catalyst modified powder sprayed MEAs exhibit similar performance throughout the polarization curve apart from the fact that catalyst modified MEA has poor performance at the kinetic region, but regained after $0.6 \mathrm{~A} / \mathrm{cm}^{2}$. In modified catalyst powder, the ionomer film covers some of the 
pores where some of the Pt becomes inactive inside the pores. This is the reason why support modified MEA exhibits better performance at lower current densities comparing to catalyst modified MEA where almost all the Pt is uncovered. The reason of the raising performance of catalyst modified MEA is the hydrophilicity difference of the powder before mixing ionomer dispersion. Pt/C (HISPEC-4000) powder is more hydrophilic than Vulcan Xc-72 carbon support; so that it shows better attraction to the hydrophilic part of ionomer and results in a better distribution and network of ionomer in the dispersion [27, 28]. So, when current density reaches the mass-transport influenced region of the polarization curve, catalyst layer needs high proton conduction, and better distribution of ionomer facilitates the performance of the catalyst modified MEA. On the other hand, due to its high hydrophobicity, Vulcan XC-72 has inferior ionomer distribution and could not increase the power as expected despite of higher electrochemical active surface area. In this case, poor ionomer distribution causes higher ohmic loss to the support modified MEA. Nevertheless, at high current density more water is produced in the catalyst layer, and internal Pt become active when the carbon supports are fully wet. This might also be a reason for the increasing performance of catalyst modified MEA comparing to support modified one.
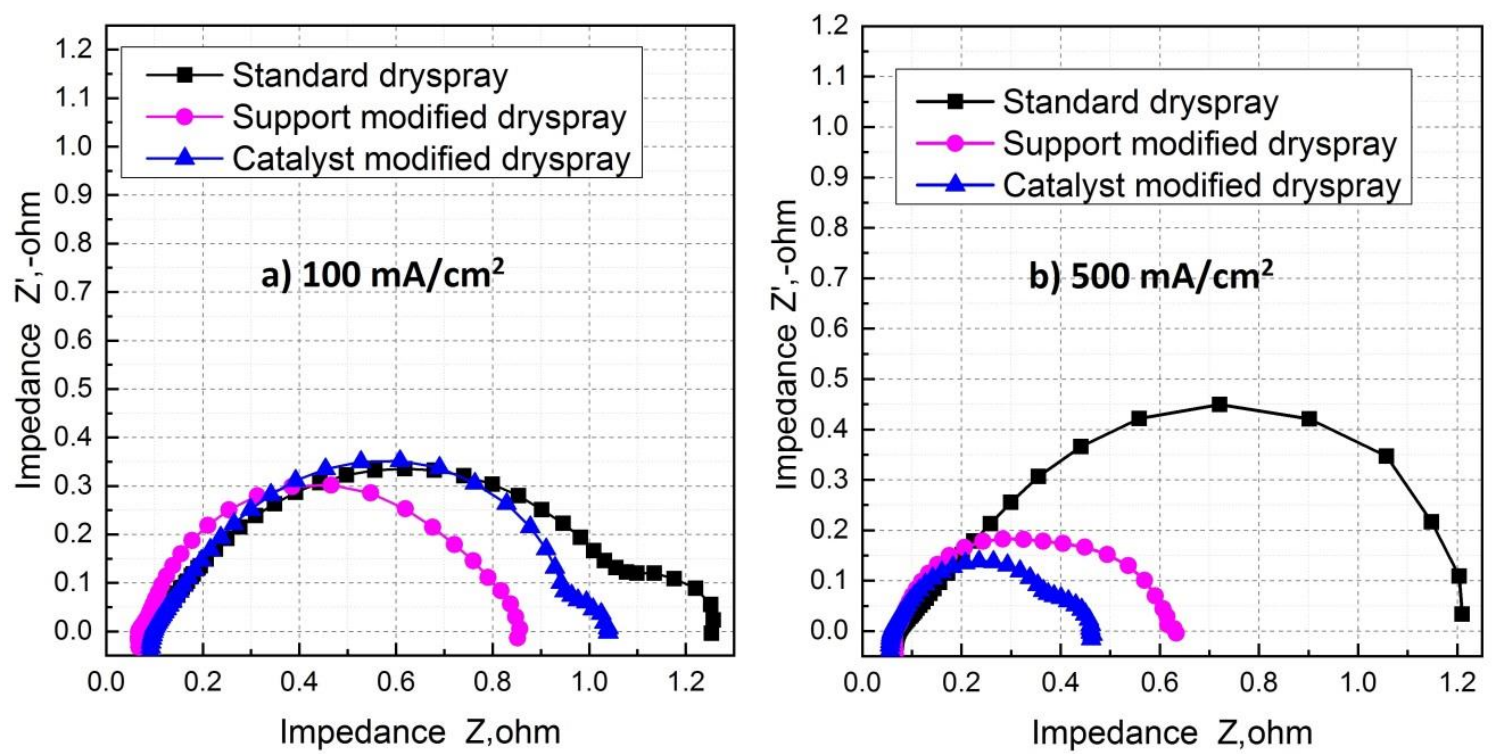
Figure 5: EIS-Nyquist plot of MEAs prepared by unmodified, support modified and catalyst modified powder in the frequency range of $100 \mathrm{mHz}$ to $100 \mathrm{KHz}$ at a current density (a) $100 \mathrm{~mA}$ and (b) $500 \mathrm{~mA}$.

4.4 The above mentioned behavior is also validated by the impedance spectroscopy studies shown in figure 5. High frequency intersection of the Nyquist plot from the Y axis (left side) represents ohmic overpotential followed by the kinetic overpotential in the mid frequency range, and finally the low frequency region (right side) demonstrates the mass transport overpotential. Nyquist plots at two current densities reveal information for different processes; at $100 \mathrm{mAcm}^{-2}$ charge transfer resistance should be significant whereas at 500 $\mathrm{mAcm}^{-2}$ mass transport should play an important role. All the curves in fig 5 were made by the raw data of the impedance spectroscopy. Considering a negligible over-potential of the anode electrode, the arcs of all MEAs should be dominated by the ORR reaction at the cathode at $100 \mathrm{~mA} / \mathrm{cm}^{2}$ current density. Interestingly, already at this low current density an additional arc at lower frequency appear for the standard and catalyst modified MEA demonstrating mass transport influences most probably by badly contacted catalytic region. When current density increases, impedance decreases subsequently. In the graph $5 \mathrm{~b}$, each arrow was illustrated as the reduced impedance of distinctive MEAs after increasing current density. The larger arrow assigns the larger reduction of impedance value, which explains better performance as well. As current density increased, the arc responsible for kinetic over potential is reduced and the arc responsible for diffusion over potential remained almost unchanged for support modified and catalyst modified MEAs. On the other hand, in case of standard dry sprayed MEA, significantly higher diffusion problem started to appear even at $500 \mathrm{~mA}$ current density. It is also justifiable by the polarization curve that shows total performance loss after $1000 \mathrm{~mA} / \mathrm{cm}^{2}$. Moreover, the Nyquist plot displays that catalyst modified powder sprayed MEA surpasses the support modified powder sprayed MEA after 
ohmic over potential zone and both of them retains better diffusion properties in mass transport zone compared to the standard dry sprayed MEA.

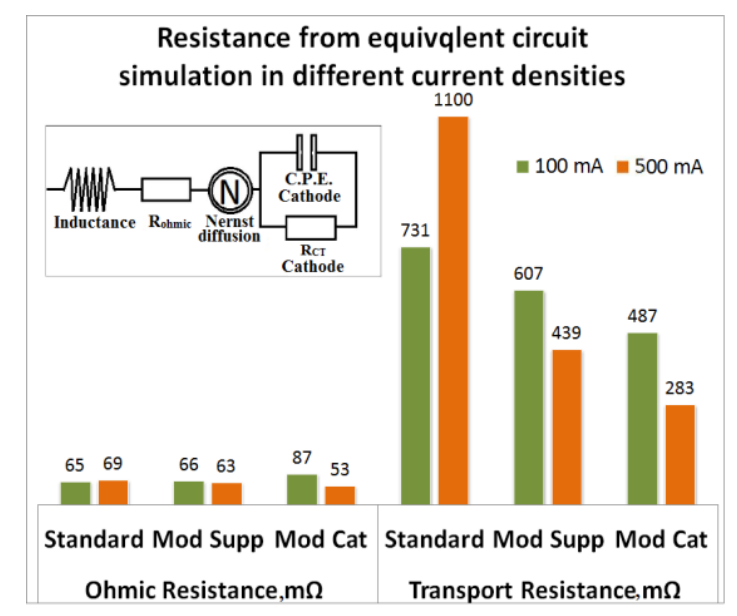

Figure 6:(Inset) Equivalent circuit used for the evaluation of impedance spectra with the resistance values for ohmic and transport over-potential at a current densities of $100 \mathrm{mAcm}^{-2}$ (green) and $500 \mathrm{mAcm}^{-2}$ (orange).

4.5 EIS-inputs of different MEAs in different current densities were fitted into the equivalent circuit which is illustrated in figure 6 (inset). Afterwards, we simulated the data in Zahner software with a common equivalent circuit to determine main parameters, namely the inductance of the set-up, the cell ohmic resistance, the charge transfer resistance and Nernst diffusion contribution of the cell within $2.5 \%$ statistical error on average. At higher frequency, the presence of $45^{\circ}$ line in the Nyquist plot in figure 5 for all MEAs indicates that the proton transport loss ( stated later) has a significant effect in these porous electrodes [23, 25]. We can observe the similar behavior from the simulated value also. The constant of diffusion $(\mathrm{Kn})$, which attributes to the Nernst diffusion component and proportional to the diffusion impedance, gives us a clear impression of the cathode electrode. Electrode with standard powder gives us the value $\mathrm{Kn}=304 \mathrm{~S}^{-1}$ whereas; electrode with modified support gives $73 \mathrm{~S}^{-1}$ and modified catalyst gives $107 \mathrm{~S}^{-1}$ at $100 \mathrm{~mA}$ current density. This consequence can also be deduced from the Nyquist plot in fig 5(a), where we can see the biggest 
contribution of diffusion impedance from the electrode with standard powder, and progressively reduced in the electrode with modified catalyst powder and minimum in case of modified support. The ohmic and the cathodic charge transfer resistance were exploited to a bar chart to demonstrate the over potential in different current densities. We can observe almost similar behavior of ohmic resistance at $100 \mathrm{~mA}$ from the simulated value. MEA fabricated with standard dry spray shows higher charge transfer resistance at lower current density which is expected due to its poor protonic conductivity, and as we increase the current density the resistance also increases drastically. On the contrary, MEA prepared with modified catalyst shows a noteworthy recovery of both ohmic and charge transfer resistance at higher current density which is also manifested in the performance in the polarization curve.
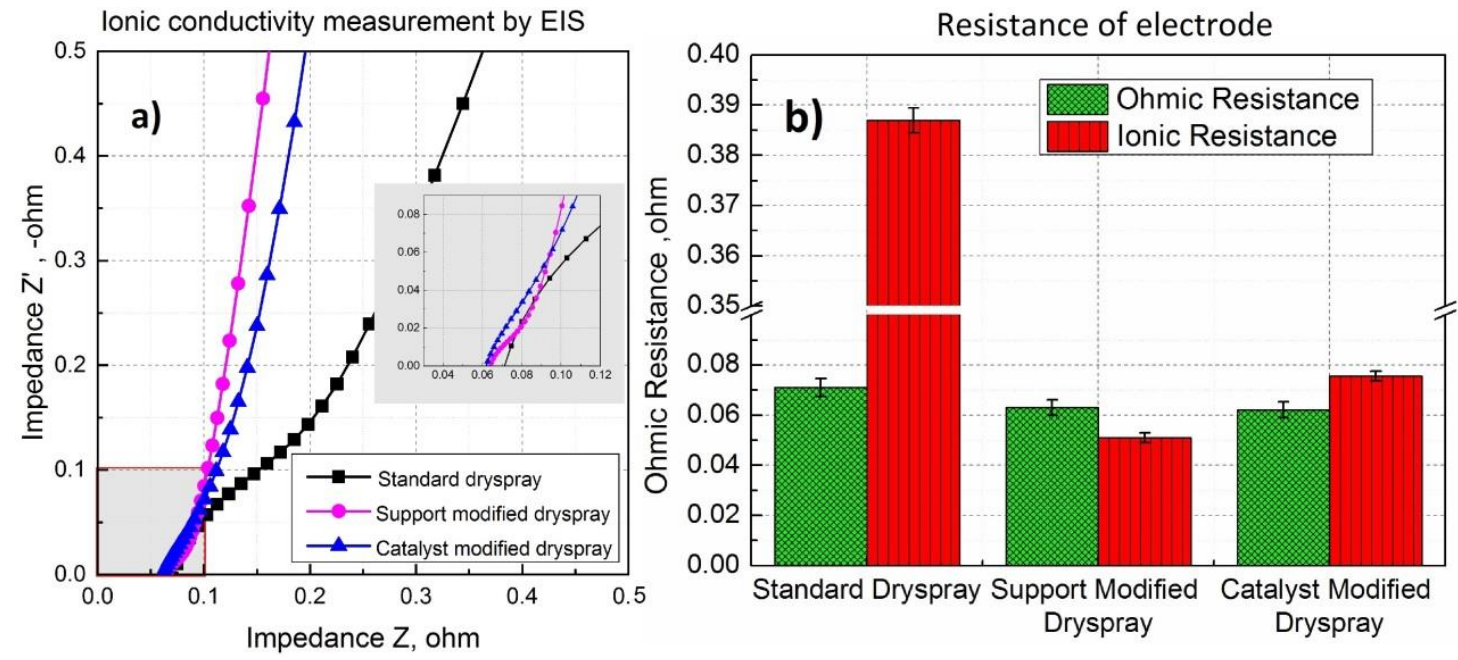

Figure 7: a) Ionic conductivity measurement by EIS of MEAs prepared with standard (the inset represents an expansion of the high frequencies region where the curvature of approximately $90^{\circ}$ is the representative of the limiting capacitive current), support modified and catalyst modified powder at $100 \%$ humidity with $\mathrm{H}_{2} / \mathrm{N}_{2}$ flow, b) distribution of electronic and ionic resistance. 
4.6 Ionic conductivity measurement of MEA is a powerful tool considered to evaluate the ionic and electronic resistance inside the catalyst layer. The effects of the inhomogeneity of the catalyst layers $[23,24]$ are more clearly observed in the impedance plots shown in fig. 7(a). The high-frequency slope of the curve for the electrode impregnated with liquid Nafion ${ }^{\circledR}$ (modified powder sprayed MEAs) is markedly steeper than electrode fabricated with solid Nafion ${ }^{\circledR}$ (standard powder sprayed MEA). Higher proton conductivity and better ionomer distribution is explained by the steeper capacitance slope in fig 7(a). At high frequencies a Warburg-like response $\left(45^{\circ} \mathrm{C}\right.$ slope) is observed, corresponding to ion migration through the catalytic layer, and at low frequency it is linear up to about half of the limiting capacitance and then curves up to a constant capacitance and resistance which corresponds to the total resistance and capacitance of the catalytic layer. Fig. 7(b) shows the calculated ohmic and ionic resistance of the catalyst layer. Characterization of the ionic resistance of catalyst layer can give an important measure of electrode quality and can provide valuable feedback for an optimized MEA structure [23, 24]. Another advantage of Nafion ${ }^{\circledR}$ impregnation by dispersion is that more of the electrochemically active catalyst layer is accessible, as can be seen from the larger slope of the limiting capacitance observed from the modified powder sprayed electrode. These characteristics can be translated into improved performance as a fuel cell cathode in modified powder sprayed MEAs in contrast with standard powder. The distribution of ohmic and ionic resistance in the fig 7(b) also coincides with the performance of different MEAs. High frequency impedance (ohmic resistance) depends on the electrical connections, proton conductivity of ionomer, ratio of ionomer and MEA compression while assembling in the cell. As the comparison of the MEAs is performed with similar conditions (e.g. torque, reaction condition and ionomer ratio), it is understandable that the ohmic resistance is similar for all MEAs. The significant difference in ionic resistance is due to the different ionomer distributions within the catalytic layer and this is the important factor for performance. The drysprayed MEA has a heterogeneous ionomer distribution and poor availability of reaction 
interface. Agglomeration of particles plays also a vital role to reduce the electrochemically active area. When the ORR produces higher current under practical cell operating conditions, the ionomer distribution becomes more important because of the contribution of resistances to the mass transport of $\mathrm{H}^{+}$and $\mathrm{O}_{2}$ through ionomer.
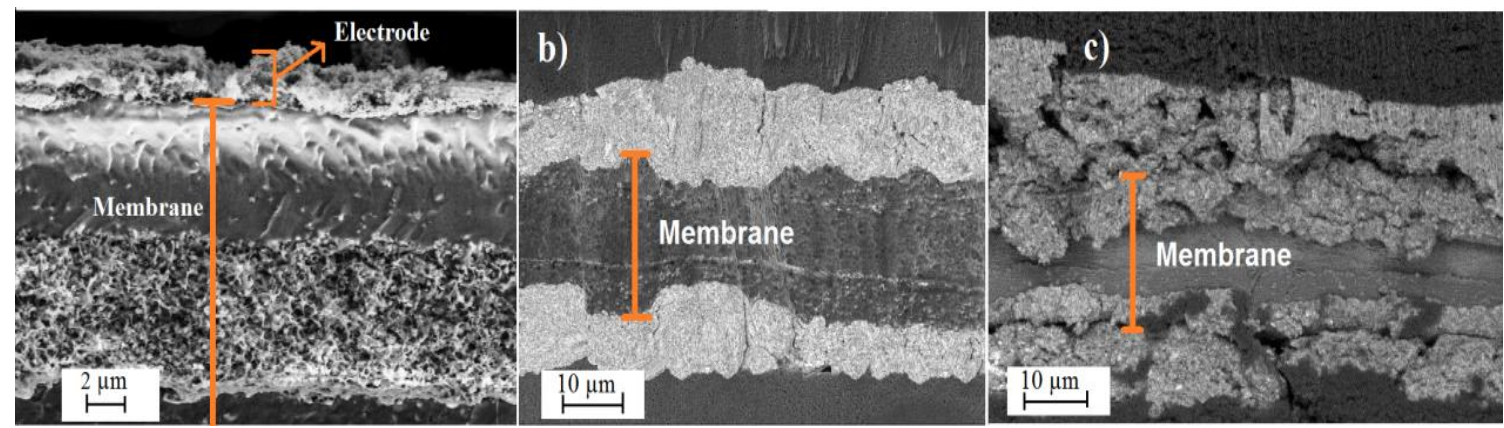

Figure 8: SEM images of ion beam cut cross-sectional of catalyst layers with same noble metal loadings of $0.3 \mathrm{mg} / \mathrm{cm}^{2}$ on one side a) inhomogeneous catalyst layer MEA sprayed with standard powder, b) sprayed with support modified, and c) sprayed with catalyst modified powder sprayed MEA; the orange bar is the thickness of membrane.

4.7 Fig. 8 demonstrates the SEM images of the cross-section of the electrodes after 48 hours of fuel cell operation. MEA prepared with dry spray coating method shows an uneven thickness in the catalyst layer. Due to the limitation of the particle size and formation of agglomerates in the humid environment, we have not yet successfully fabricated a flat and uniform electrode layer. We expect that, "a better control of the humidity on the coating laboratory" may solve this problem. However, MEA prepared with standard powder shows a very non-uniform electrode layer with a large difference in thickness. In some areas the thickness of the CL goes down to $2 \mu \mathrm{m}$, in contrast to some other areas where agglomerated powder causes CCM thickness go as high as $30 \mu \mathrm{m}$ (not in the picture). This variety of thickness is also responsible for heterogeneous current densities throughout the MEA, which causes instability of performance and hence shows higher degradation in electrodes and membrane as well. In contrast, the dispersion modified catalytic layers also show thickness 
heterogeneity but there microscopic structure is more homogeneous as reflected by better performance and stability.

It was reported by Uchida et al. that a good network and uniformity of Nafion ${ }^{\circledR}$ on $\mathrm{Pt}$ particles could be achieved by using "colloid" form of Nafion ${ }^{\circledR}$ in the catalyst "ink". There should be an optimum thickness of the ionomer film for superior performance [29, 30]. Watanabe has reported that $0.2 \mu \mathrm{m}$ is the critical thickness of the Nafion ${ }^{\circledR}$ film on the catalyst surface up to which the diffusion process of reactant gases to the catalyst sites is not the ratedetermining step [25]. We believe that, if the Pt particle and ionomer distribution are further improved and we singularize the agglomerates during dry spraying more efficiently, it will be possible to further increase the performance of dry sprayed MEA.

\section{Conclusion:}

This work shows how the inclusion of dispersed liquid Nafion ${ }^{\circledR}$ into catalyst powder, followed by drying and powder spraying enhances the fuel cell performance. Using liquid Nafion ${ }^{\circledR}$ instead of solid Nafion introduces ionomer films around the catalyst support as well as catalyst agglomerates hereby induces better ionomer distribution throughout the catalyst layer. It is plausible that, due to partial ionomer film forming property over catalyst particles, electrochemically active interface zone increases and so does the performance. We can justify the progression functioning as,

1) Reduction of the subsequent agglomeration of ionomer powder as well as catalyst particles and securing better distribution of ionomer by using dispersion media,

2) Thin film-ionomer structures by replacing large solid ionomer particles with Nafion ${ }^{\circledR}$ dispersion. Enhance the ionic conductivity, electrochemical properties and diffusion properties by coating catalyst and/or support particles with thin ionomer film. 
However, along with better performance, the novel processes can ease the powder preparation technique by avoiding the cryogenic grinding of Nafion ${ }^{\circledR}$ which is a lengthy process. MEA prepared with dry spray coating technique has a significant potentiality in industrial manufacturing as it is a fast, easy, inexpensive and fully automatic process. Nevertheless, there are some more opportunities to enhance performance by improving catalyst-ionic structure, which should be looked into our future work.

1. Improve the distribution and homogeneity of ionomer network.

2. Fabricating $100 \mathrm{~nm}$ ionomer particles by spray drying the ionomer dispersion. (Spray drying is a method of producing a dry powder from a liquid or slurry by spraying and drying simultaneously).

3. Preferential non-uniform coating of ionomer over carbon support particle by spray dry technique.

\section{Funding:}

Corresponding author's PhD thesis is funded by DLR.DAAD research fellowship 2015.

\section{Reference:}

1. N. Konno, S. Mizuno, H. Nakaji and Y. Ishikawa, Development of Compact and HighPerformance Fuel Cell Stack, SAE Int. J. Alt. Power. 4(1) (2015) 123-129. https://doi.org/10.4271/2015-01-1175

2. R. O’Hayre, S.W. Cha, W. Colella and F.B.Prinz, Fuel cell Fundamentals, second ed., John Wiley \& Sons, New Jersy, 2009, Chapter 1. ISBN13: 9780470258439 
3. J. Kurtz, S. Sprik, C. Ainscough, G. Saur, Fuel Cell Electric Vehicle Evaluation, DOE Project 2012, Annual Merit Review, 2015. National Renewable Energy Laboratory.

4. J.H. Wee, K.Y. Lee and S.H. Kim and A. Kaufman, Fabrication method for low-Pt-loading electrocatalysts in proton exchange membrane fuel cell, J. Power Sources, 165 (2007) 667677. https://doi.org/10.1016/j.jpowsour.2006.12.051

5. Z. Qi and A. Kaufman, Low Pt loading high performance cathodes for PEM fuel cells, J. Power Sources, 113(1) (2003) 37-43. https://doi.org/10.1016/S0378-7753(02)00477-9

6. Y. Liu, M.W. Murphy, D.R. Baker, W.Gu, C. Ji, J. Jorne and Hubert A. Gasteiger, Proton conduction and oxygen reduction kinetics in PEM fuel cell cathodes: Effects of ionomer-tocarbon ratio and relative humidity, J. Electrcohem. Soc. 156 (8) (2009) B 970-980. DOI: $10.1149 / 1.3143965$

7. S. Litster, G. McLean, PEM fuel cell electrodes, J. Power Sources 130 (2004) 61-67. https://doi.org/10.1016/j.jpowsour.2003.12.055

8. S. Shukla, K. Domican, K. Karan, S. Bhattacharjee, M. Secanell, Analysis of Low Platinum Loading Thin Polymer Electrolyte Fuel Cell Electrodes Prepared by Inkjet Printing, Electrochimica Acta 156 (2015) 289-300. https://doi.org/10.1016/j.electacta.2015.01.028

9. K. L. More, R. Borup, and K. S. Reeves, Identifying Contributing Degradation Phenomena in PEM Fuel Cell Membrane Electrode Assemblies via Electron Microscopy, ECS Transactions, 3(1) (2006) 717-733. DOI: 10.1149/1.2356192

10. T. Muzaffer, T. Kadyk and M. Eikerling, Physical Modeling of the Proton Density in Nanopores of PEM Fuel Cell Catalyst Layers, Electrochimica. Acta, 245 (2017) 1048-1058. https://doi.org/10.1016/j.electacta.2017.05.052 
11. K. Talukdar, H.J. Kim, Y.H. Kim, H.C. Lee and S.J. Choi, Polyacrylamide/Nafion ${ }^{\circledR}$ SemiInterpenetrating Networks as Proton-Conducting Membrane of Direct Methanol Fuel Cell, Sci. Adv. Mater. 6 (2014) 2389-2394. https://doi.org/10.1166/sam.2014.2190

12. K. Talukdar, H.J. Kim, Y.H. Kim, Y.J. Park, H.C. Lee and S.J. Choi, Proton-Conducting Membrane from Nafion ${ }^{\circledR} /$ Polystyrne Sulfonate Composite for Fuel Cell Applications, J. Nanoelectron. \& Optoelectron. 10 (2015) 535-540. https://doi.org/10.1166/jno.2015.1797

13. T. Morawietz, M. Handl, C. Oldani, K.A. Friedrich and R. Hiesgen, Quantitative In-Situ Analysis of Ionomer Structure in Fuel Cell Catalytic Layers, ACS Appl. Mater. Interface 8(40) (2016) 27044-27054. DOI: 10.1021/acsami.6b07188

14. E. Güzlow, M. Schulze, N. Wagner, T. Kaz, A. Schneider and R. Reissner, New dry preparation techniques for membrane electrode assemblies for PEM fuel cells, Fuel Cell Bulletin 15 (1999) 8-12. https://doi.org/10.1016/S1464-2859(99)80002-9

15. D. Bevers, N. Wagner and M. Von Bradke, Innovative production procedure for low cost PEFC electrodes and electrode/membrane structures, Int. J Hydrogen Energy 23 (1998) 5763. https://doi.org/10.1016/S0360-3199(97)00028-1

16. N. Wagner. T. Kaz, K.A. Friedrich, Investigation of electrode composition of polymer fuel cells by electrochemical impedance spectroscopy, Electrochimica Acta 53 (2008) 7475-7482. https://doi.org/10.1016/j.electacta.2008.01.084

17. S. Holdcroft, Fuel Cell Catalyst Layers: A polymer Science Perspective, Chem. Mater. 26 (2014) 381-393. DOI: $10.1021 / \mathrm{cm} 401445 \mathrm{~h}$

18. J. Larminie and A. Dicks, Fuel Cell system explained, John Wiley, New Jersey, 2000, Chapter 2. ISBN-13: 978-0471490265 
19. E.F. Hansen, S. Walston and M.H. Bishop, Matte Paint, WAAC Newsletter 2(18) 1996. http://cool.conservation-us.org/waac/wn/wn18/wn18-2/wn18-207.html

20. T. Brock, M. Groteklaes and P. Mischke, (Edited U. Zorll) European Coating Handbook, Th. Schäfer, Hannover, 2000, Chapter 3.3. ISBN: 3-87870-559-X

21. E. Gülzow and T. Kaz, New results of PEFC electrodes produced by the DLR dry preparation technique, J. Power Sources 106 (2002) 122-125. https://doi.org/10.1016/S03787753(01)01030-8

22. E. Güzlow, M. Schulze, N. Wagner, T. Kaz, R. Reissner, G. Steinhilber, A. Schneider, Dry layer preparation and characterisation of polymer electrolyte fuel cell components, J. Power Sources 86 (2000) 352-362. https://doi.org/10.1016/S0378-7753(99)00451-6

23. M.C. Lefebvre, R.B. Martin and P.G. Pickup, Characterization of Ionic Conductivity Profiles within Proton Exchange Membrane Fuel Cell Gas Diffusion Electrodes by Impedance Spectroscopy, Electrochem. Solid St. 2(6) (1999) 259-261. DOI: 10.1149/1.1390804

24. G. Li and G. Pickup, Ionic Conductivity of PEMFC Electrodes; Effect of Nafion Loading, J. Electrochem Soc. 150(11) (2003) C745-752. DOI: 10.1149/1.1611493

25. M. Watanabe, H. Igarashi, K. Yosida, An Experimental Prediction of the preparation condition of Nafion-coated catalyst layers for PEFCs, Electrochim. Acta 40(3) (1995) 329334. https://doi.org/10.1016/0013-4686(94)00271-2

26. K. R. Cooper, Experimental methods and data analyses for polymer electrolyte fuel cells, Southern pinesm N.C. Schribner Associates, 2005. OCLC: 764047139 
27. Y.C. Park, H. Tokiwa, K. Kakinuma and M. Watanabe, Effects of carbon support on Pt distribution, ionomer coverage and cathode performance for polymer electrolyte fuel cells, J. Power Sources. 315 (2016) 179-191. https://doi.org/10.1016/j.jpowsour.2016.02.091

28. K. Malek, T. Mashio and M. Eikerling, Microstructure of catalyst layer in PEM fuel cells redefined: A computational approach, Electrocatal. 2 (2011) 141-157. DOI 10.1007/s12678011-0047-0

29. Z. Siroma, T. Sasakura, K. Yasuda, M. Azuma and Y. Miyazaki, Effects of ionomer content on mass transport in gas diffusion electrodes for proton exchange membrane fuel cells, J. Electroanal. Chem. 546 (2003) 73-78. DOI: 10.1016/S0022-0728(03)00147-5

30. M. Uchida, Y. Aoyama, N. Eda and A. Ohta, New Preparation Method for PolymerElectrolyte Fuel Cells, J. Electrochem. Soc. 142(2) (1995) 463-468. DOI: 10.1149/1.2044068 